
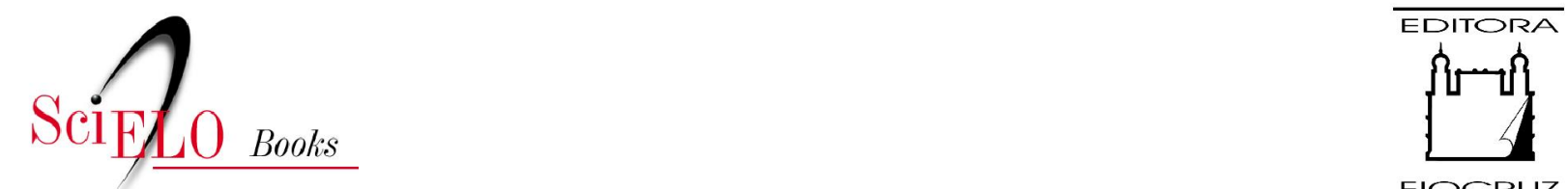

FIOCRUZ

\title{
1 As políticas de saúde e o ensino da saúde no Brasil (1970-1980)
}

\author{
Tânia Celeste Matos Nunes
}

\section{SciELO Books / SciELO Livros / SciELO Libros}

NUNES, T. C. M. As políticas de saúde e o ensino da saúde no Brasil (1970-1980). In: Democracia no ensino e nas instituições: a face pedagógica do SUS [online]. Rio de Janeiro: Editora FIOCRUZ, 2007, pp. 23-45. ISBN: 978-85-7541-530-6. Available from: doi: 10.7476/9788575415306. Also available in ePUB from: $\underline{\text { http://books.scielo.org/id/7p3wt/epub/nunes-9788575415306.epub. }}$

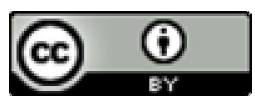

All the contents of this work, except where otherwise noted, is licensed under a Creative Commons Attribution $\underline{4.0 \text { International license. }}$

Todo o conteúdo deste trabalho, exceto quando houver ressalva, é publicado sob a licença Creative Commons Atribição 4.0.

Todo el contenido de esta obra, excepto donde se indique lo contrario, está bajo licencia de la licencia Creative Commons Reconocimento 4.0. 


\section{As Políticas de Saúde e o Ensino da Saúde no Brasil (1970-1980)}

$\mathrm{Na}$ década de 70 , a sociedade brasileira vivenciou momentos difíceis, com 0 aprofundamento de medidas implantadas progressivamente pelo regime militar depois de sancionado o Ato Institucional n. 5. Em dezembro de 1968, o país assistiu ao fechamento do Congresso Nacional, acompanhado do comprometimento das liberdades democráticas, com a cassação de políticos e professores e grandes prejuízos à ciência e à educação brasileira. A reação a tais medidas, ainda na década de 60 , se deu principalmente pelo enfrentamento nas passeatas e nas manifestações artísticas, com o protagonismo dos intelectuais, artistas e estudantes. Também no final da mesma década foi sancionada a Reforma Universitária, produzindo seus maiores efeitos durante a década seguinte, no que se refere à organização das universidades com suas escolas, seus departamentos e seus currículos.

Na saúde, as décadas de 70 e 80 foram percorridas de forma peculiar, sendo emblemática a reação de grupos mobilizados pelas suas entidades e também em instituições governamentais, tendo no Centro Brasileiro de Estudos em Saúde (Cebes), criado em 1977, e na Associação Brasileira de Pós-Graduação em Saúde Coletiva (Abrasco), fundada em 1979, seus exemplos mais marcantes.

Sob a liderança dessas entidades, muitos eventos foram organizados, com maior freqüência na década de 80 , permitindo que o tema da democracia circulasse entre profissionais engajados politicamente a favor da causa democrática, nos serviços e nas academias, tomando a dimensão de um amálgama que perpassou inúmeros espaços, configurando também um verdadeiro movimento que culminou com três grandes conquistas para a sociedade brasileira: a idéia de Reforma Sanitária, o Sistema Único de Saúde, sancionado como lei em 1990, e a inscrição da saúde como direito, na Constituição de 1988.

Nos anos 80 processa-se a democratização lenta e gradual propugnada pelos militares. Nesse período os grupos progressistas que queriam a Reforma 
Sanitária em bases democráticas ganharam fôlego, a partir de construções emanadas de sua própria organização, tendo, nas Ações Integradas de Saúde (AIS), um mecanismo potente de preparação do sistema de saúde para mudanças qualitativas no seu processo de planejamento e operação. A $8^{a}$ Conferência Nacional de Saúde, realizada em 1986, constitui um momento político ímpar, de aglutinação de forças representativas dos movimentos organizados de trabalhadores, da sociedade organizada, dos políticos e de dirigentes comprometidos com o campo progressista. Foi então possível delinear as bases de um sistema de saúde coerente com as proposições da Reforma Sanitária que vinha sendo gestada no interior do chamado movimento sanitário, desde a década de 70 .

O avanço das políticas de saúde se deu de forma muito associada ao campo especializado da formação de recursos humanos para a saúde pública, representado pelos departamentos de Medicina Preventiva, as escolas de Saúde Pública, os núcleos de Estudos em Saúde Coletiva (Nescs), que organizaram com expressiva interlocução fortemente mediada pelo Cebes e pela Abrasco, notadamente na década de 80 .

Desse modo, revisitar o ensino da saúde pública nas décadas de 70 e 80 através de dados, documentos, depoimentos, registros e anotações sobre cursos e escolas permitiu também vislumbrar uma realidade recortada por uma intensa atividade política de oposição ao regime militar então vigente, com projeções no aparelho de Estado representadas pela formação de grupos associados em projetos considerados progressistas.

Convivendo com um contexto político adverso, os movimentos que decorreram dessas articulações possibilitaram a construção de experiências inovadoras nos setores da saúde e da educação, com repercussões na formação de quadros para os serviços públicos de saúde. Sendo assim, compreender as transformações no campo do ensino de saúde pública durante aquele período exige, de outra parte, certo investimento no entendimento do processo de reforma geral do sistema de saúde brasileiro.

Esse período teve como principal característica uma inquietação produtiva dos profissionais que trabalhavam nas instituições de saúde, o que pode ser observado na seqüência de projetos e iniciativas articulados às políticas públicas que culminaram com a aprovação do sus na década de 90 . O conjunto de experiências aqui analisadas revela que, na dinâmica de funcionamento do próprio Estado, a perspectiva conservadora convivia com as possibilidades de renovação e, através das contradições produzidas pelo momento político, criavam-se as condições para a produção de alternativas de mudanças dessa realidade. 
$\mathrm{Na}$ década de 70 , os espaços acadêmicos viveram processos de fortalecimento político ideológico, com a constituição de grupos que se aproximavam, por identidade, em torno da idéia de democracia. O processo interativo entre espaços acadêmicos, estruturas de governo e grupos organizados da sociedade contribuiu para as mudanças que conformaram as temáticas dos cursos nos anos 80 , em um contexto de "abertura lenta e gradual", arbitrada pelo regime político, e que se traduziu no âmbito da saúde por um movimento pela sua democratização.

Esses grandes eixos abrigaram a organização de inúmeras experiências de pesquisa e ensino, e, na dinâmica dos 'centros formadores', favoreceram a formação de equipes, e a recriação de suas práticas acadêmicas, ainda que influenciadas por outros fatores, como a dinâmica das instituições que abrigavam esses mesmos aparelhos formadores, e pelas possibilidades individuais e de grupos que compunham cada um dos centros de formação.

$\mathrm{Na}$ segunda metade da década de 70 , intensificaram-se as discussões em torno do sistema nacional de saúde da época, trazendo para o âmbito do Ministério da Saúde e das secretarias estaduais de Saúde as propostas de atenção primária à saúde, em cumprimento às orientações emanadas da Conferência Mundial de Saúde realizada em Alma-Ata, em 1978: todos os governos devem formular políticas, estratégias e planos nacionais de saúde para lançar e sustentar os cuidados primários de saúde em coordenação com outros setores. Para esse fim, se faz necessário agir com vontade política, mobilizar os recursos do país e utilizar racionalmente os recursos externos disponíveis (OMS/ Unicef, 1979).

O Brasil acatou as recomendações feitas na Conferência de Alma-Ata quanto à regionalização dos serviços e à expansão de cobertura, reiterando posição anterior tomada por ocasião da III Reunião de Ministros de Saúde das Américas, realizada em 1972, no Chile, e registrada no Plano Decenal de Saúde para as Américas.

A Conferência de Alma-Ata marcou profundamente a organização do sistema de saúde brasileiro, e a adoção de suas recomendações pelo nosso governo deu início a uma seqüência de processos organizativos e políticos que culminaram com um novo sistema de saúde na década de 80 . As bases doutrinárias do novo sistema foram referendadas pela plenária da $8^{a}$ Conferência Nacional de Saúde e sua aprovação pelo Congresso Nacional se deu em 1990.

Apesar de a incorporação das recomendações de Alma-Ata ter ocorrido, no Brasil, ao final dos anos 70 , é possível observar que, durante toda essa década, 
inúmeras experiências, antecipadamente, problematizaram a forma de organização e gestão do sistema de saúde, com suas políticas coordenadas pelos ministérios da Saúde e da Previdência e Assistência Social.

Vale ressaltar que, nesse período, aprofundou-se a interferência estatal, amparada na Constituição de 1969, que delegou à iniciativa privada a prioridade para organizar e explorar as atividades econômicas, ficando o Estado com o papel suplementar na prestação de serviços e, no campo da saúde, como o grande comprador dos serviços do setor privado, via Previdência Social (Oliveira \& Fleury, 1986).

Essa condução política teve um papel fundamental no desenvolvimento de "um estilo padrão de organização da prática médica orientada em termos da lucratividade do setor saúde, propiciando a capitalização da medicina e oferecendo privilégios ao produtor privado dos serviços" (Oliveira \& Fleury, 1986: 235), com reflexos no campo da saúde pública, tornando-se temática de estudos e presença significativa na conformação do ensino e da pesquisa nessa área (Abrasco, 1983).

É importante destacar que o sistema de saúde então vigente vinha passando por sucessivos ajustes desde a década de 60 , de modo a adaptar-se às políticas de governo de sua época. Exemplos deste fenômeno foram a substituição dos antigos Institutos de Aposentadorias e Pensões (IAPs) pelo Instituto Nacional de Previdência Social (INPS), em 1966; a criação do Ministério da Previdência e Assistência Social (MPAS) pela Lei 6.025, de 25 de junho de 1974; a criação do Sistema Nacional de Saúde pela Lei 6.229 , de 1975 , com o estabelecimento da divisão dos campos institucionais da saúde coletiva e da saúde das pessoas (Oliveira \& Fleury, 1986a; Vilaça, 1994).

Essas reformas jurídico-administrativas não foram capazes de viabilizar, em curto prazo, o sistema único de saúde, tampouco absorveram as insatisfações dos trabalhadores. Aos poucos, iam aflorando as contradições do próprio sistema previdenciário, que já não conseguia garantir o seu financiamento nos moldes estabelecidos.

Os resultados das eleições de 1974 foram indicativos das insatisfações com o governo militar. Este fato náo passou despercebido pela estrutura de poder, que, a partir daquele momento, começou a produzir medidas racionalizadoras, criando condições para o surgimento de espaços para a realização de embates políticos e para a conformação de alianças entre grupos que se colocavam nas estruturas de poder do governo, e se identificavam com idéias que vinham sendo discutidas em outros setores da sociedade que ansiavam por mudanças políticas e sociais.

É preciso lembrar que, nesse período, dois fatores externos produziram grande impacto nas bases da economia brasileira, especialmente no processo 
de exportação e inserção do país na economia mundial. A chamada crise do petróleo e a perda do poder de troca de produtos como o café, o açúcar e o algodão atingiram seriamente o modelo econômico que definia a integração do Brasil ao mercado internacional. A crise chegou a ponto de produzir dificuldades na capacidade de financiamento do Estado brasileiro, inclusive para o financiamento das importações. Esses fatores se associaram à crise política interna, levando o governo a editar o II Plano Nacional de Desenvolvimento (II PND), ${ }^{1}$ com o privilégio de medidas que previam uma redistribuição de renda e reservavam papel de destaque à previdência, mantendo a coerência quanto à escolha desse canal de legitimação, entre governo e sociedade (Oliveira \& Fleury, 1986).

Por ocasião do anúncio do II PND, em 1974, o ministro da Previdência proferiu um discurso na Escola Superior de Guerra, recomendando, como medidas necessárias, a redução das desigualdades sociais e a ampliação da área de atendimento das necessidades sociais da população em termos das escolas, da habitação, dos níveis sanitários básicos, da proteção médica e previdenciária, colocando-as como pressupostos para o processo de distensão política (Oliveira \& Fleury, 1986).

No Plano também foram definidos os campos de atuação dos ministérios da Saúde e da Previdência Social, ficando o primeiro com um "caráter eminentemente normativo, com ação executiva preferencialmente voltada para as medidas e para o atendimento de interesse coletivo, inclusive vigilância sanitária, e o Ministério da Previdência e Assistência Social, com atuação voltada principalmente para o atendimento médico assistencial individualizado" (Oliveira \& Fleury, 1986: 239), o que demarcava também o perfil de financiamento governamental e das estruturas prestadoras de atenção à saúde, coerentes com as políticas dos dois ministérios.

A explicitação de áreas de importância para os investimentos sociais no II PND, no entanto, se evidenciou como uma alternativa à construção de projetos articuladores de algumas representações de trabalhadores no interior do governo, criando espaço para a formulação de programas de extensão de

\footnotetext{
${ }^{1}$ O II Plano Nacional de Desenvolvimento (II PND) foi anunciado pelo então presidente Ernesto Geisel, em 10/9/1974, consubstanciando "metas tentativas" a serem alcançadas entre 1975 e 1979. Em sua primeira parte, o PND refere o Brasil como potência emergente e, dentre outros temas, aborda uma estratégia de desenvolvimento social, em que estão tratados os temas de distribuição de renda, emprego e salários, valorização dos recursos humanos. No capítulo XIII discute o emprego e os recursos humanos vinculados às perspectivas de crescimento do país. O capítulo XIV aborda a Política Científica e Tecnológica (II PND - República Federativa do Brasil, 1974).
} 
cobertura, a exemplo do Programa de Interiorização da Saúde e Saneamento (Piass), e uma conseqüente aproximação do Ministério da Saúde com as secretarias estaduais de Saúde, na gestão desses programas.

Coerente com o peso que representava o pensamento do Ministério do Planejamento nas estruturas burocráticas, a partir de 1974, o governo Geisel também valorizou a Secretaria de Planejamento da Presidência da República, apoiando ações voltadas para o fortalecimento das políticas públicas, abrindo espaços no interior do governo para a formulação de projetos, que, a partir de 1975, começaram a ser viabilizados (Brasil, 1974).

Nesse contexto, o ministro da Saúde Almeida Machado, que cumpriu mandato entre março de 1974 e março de 1979, convidou o então professor da Faculdade de Saúde Pública da Universidade de São Paulo (FSP/USP), o Dr. José Carlos Seixas, para o cargo de secretário-geral do ministério. Em 1975, o Dr. Valter Leser assumiria, pela segunda vez, a função de secretário de Saúde do Estado de São Paulo, permanecendo até 1979, graças ao apoio do governador Paulo Egydio Martins.

Nessas oportunidades, retomavam-se convicções amadurecidas no cenário político mais amplo. Leser, por exemplo, retomou propostas oriundas de seu primeiro mandato, relativas à necessidade de contar com profissionais de saúde pública para alguns postos de trabalho da Secretaria de Saúde. De sua determinação nasceu uma estratégia para a formação desses quadros que viria pautar a ação da Secretaria Estadual de Saúde junto à FSP/USP nesse novo período de governo.

Os anos de 1974 e 1975 foram de intensa atividade para o setor saúde. No período de 5 a 9 de agosto de 1975 , por exemplo, realizou-se a $5^{\text {a }}$ Conferência Nacional de Saúde, quando também ocorria com certa clareza a mudança do discurso de governo em relação às questões de Saúde e Educação, incorporando preocupações com o indivíduo e com a formação de recursos humanos de qualidade. Naquela oportunidade, o Dr. Edson Machado, representante do Ministério da Educação, proferiu uma conferência destacando alguns pontos que merecem ser referidos, pela forma com que estavam traduzidas as mensagens de governo, no plano educacional, na relação com a saúde:

A formulação de uma política de educação numa sociedade que vem atravessando profundas transformações em sua paisagem sócio-políticoeconômica e cultural não é tarefa fácil, principalmente se levarmos em conta que a educação é simultaneamente, um meio e um fim. É meio quando considera apenas os aspectos produtivos, de preparação de mão de obra para o atendimento à demanda e da manutenção do steady state entre o sistema 
formador de recursos humanos e o sistema utilizador desses recursos. De outro lado, não se pode perder de vista, que a educação é também um fim, é consumo, é a melhor forma de proporcionar ao indivíduo a sua auto-realização. Sob esse aspecto, uma política de educação pressupõe uma filosofia da educação, edificada fundamentalmente sob as bases vivas e caracteres contingentes da coletividade, auscultando mesmo as mínimas vibrações sociais, num comportamento "de baixo para cima" a fim de incorporar as grandes linhas de preocupação dessa coletividade. (Brasil, 1993a: 67)

o pensamento expresso pelo Dr. Edson Machado naquela oportunidade se traduzia também na postura que algumas instâncias de governo passaram a adotar, sob a orientação do Conselho de Desenvolvimento Econômico e Social, órgão de assessoramento ao presidente da República (Brasil, 1974). Criava-se, gradualmente, um espaço de abertura para a revitalização das instituições de Ciência e Tecnologia, entre as quais estava a Fundação Instituto Oswaldo Cruz. A sua fala também alertava para a necessidade de formular programas que abrigassem propostas de capacitação de uma mãode-obra com formação sólida, avançando para além da visão instrumental até então existente.

A visão defendida por Machado representava a retórica de governo. Os avanços previstos pelo desenvolvimento do II PND não pretendiam mudar a direção das questões sociais, mas apontavam para a gradual importância estratégica que adquiria o tema recursos humanos no quadro da reforma geral do Estado, inclusive no campo da saúde. Referindo-se a esse fenômeno, Teixeira (1982: 51) ressalta que:

a valorização dos recursos humanos enquanto força de trabalho do país, fundamenta-se nas idéias que embasam o planejamento social originário do pós-guerra: os gastos com "capital humano" que contribuem para o próprio desenvolvimento econômico; trata-se de promover a incorporação das chamadas "populações de baixa renda" à dinâmica da produção capitalista, seja como produtor direto, seja como consumidor.

Na visão da autora, saúde e educação seriam objetos de consumo específico, que exigiriam uma qualificação da força de trabalho afinada à ótica economicista, investindo em capital humano - ao mesmo tempo em que se promovia a ideologia da ascensão social, de forma a contribuir ainda para atenuar tensões da vida em sociedade (Teixeira, 1982).

Essa percepção de dupla face que aparecia nas políticas de governo permitiu o surgimento de iniciativas no interior das equipes que se organizaram através de projetos que passaram a compor certo caminho de modernização do Estado, nessa fase, incorporando dimensões sociais, não incluídas no I PND 
$(1972 / 1974) .^{2}$ Essa perspectiva se fundamentava no item relativo à Política de Valorização de Recursos Humanos, o qual estabelecia que "nas áreas de Saúde Pública e Assistência Médica da Previdência, cuidar-se-á da reforma de estruturas, para dar capacidade gerencial a esses setores, a exemplo do que já se vem fazendo na Educação, especialmente quanto às Universidades" (Brasil, 1974: 72).

Ainda no seu capítulo XIV, da Ciência e Tecnologia, o I PND estabelecia que era "necessário atuar na base de projetos bem definidos e com orçamento delimitado", recomendando, para a área de tecnologias de áreas sociais, a ênfase na saúde e educação, assim definida: "no campo da saúde, desenvolver programas de pesquisa orientados para a eliminação de endemias, como a esquistossomose e o mal de Chagas, assim como sobre a nutrição de grandes contingentes populacionais" (Brasil, 1974: 137).

Para atender a essas recomendações, o governo impulsionou o desenvolvimento da pesquisa, transformando o Conselho Nacional de Pesquisas em Conselho Nacional de Desenvolvimento Científico e Tecnológico (CNPq), e propondo a execução do II Plano Básico de Desenvolvimento Científico e Tecnológico (II PBDCT). Consubstanciando os programas e projetos prioritários do Sistema Nacional de Ciência e Tecnologia, nas áreas dos diferentes ministérios, através do II PBDCT, o governo disponibilizou recursos financeiros de 1975 a 1980 (Brasil, 1974).

Essas definições criaram condições favoráveis ao surgimento de projetos importantes no interior do governo, com ações de intervenção na assistência à saúde, produzindo impacto nas instituições de Saúde e de Ciência e Tecnologia. Fruto desse contexto, e cumprindo diretrizes governamentais, constantes do II PND, a Secretaria de Planejamento da Presidência da República investiu no reforço de instituiçães como a Fundação Instituto Oswaldo Cruz e a Financiadora de Estudos e Projetos (Finep), resultando na formulação do Programa de Estudos Sócio-Econômicos em Saúde (Peses) e do Programa de Estudos e Projetos Populacionais e Epidemiológicos (Peppe), financiados pela Finep e executados pela Ensp (Peses, 1978).

Também em 1975, instituiu-se, na Ensp, o Programa Nacional de Cursos Descentralizados. Estes cursos se regulamentaram por convênios entre aquela Escola, as secretarias estaduais de Saúde e as universidades públicas sediadas nos estados da federação, iniciando pelo Pará e Rio Grande do Sul, e expandindo-se, nos anos subseqüentes, a quase todos os estados da Federação.

\footnotetext{
${ }^{2}$ O I Plano Nacional de Desenvolvimento (I PND) enfocou a Política Tecnológica Nacional na implantação de Centros de Tecnologia em áreas de infra-estrutura e indústrias básicas, como sejam Energia Elétrica, Tecnologia Nuclear, Petróleo, Telecomunicações, Siderurgia, Pesquisa Mineral, Pesquisa Espacial, e indicou a necessidade de reformulação da carreira de pesquisador, para assegurar-lhe condições de trabalho satisfatórias (Diário oficial, suplemento, de 17 de dezembro de 1971, I PND, 72/74).
} 
Durante um longo período, a Ensp, a FSP/USP e alguns departamentos de Medicina Preventiva das universidades ofereceram cursos de formação de sanitaristas que eram destinados a preparar profissionais para a estruturação do sistema nas três esferas de governo.

O Programa de Cursos Descentralizados da Ensp expandiu a formação desses quadros no âmbito estadual e, por força do convênio que envolvia a Fiocruz, as secretarias estaduais e algumas universidades, também favoreceu a integração ensino x serviço na absorção de docentes e na formatação de currículos mais voltados para as realidades regionais (Abrasco, 1984).

No plano da organização dos serviços de saúde, o Ministério da Saúde, durante a década de 70 , buscou elementos de formulação de uma nova política. De início, diversos setores do ministério procuraram se inspirar na reconhecida experiência desenvolvida em Montes Claros ( $M G)$, que, por sua vez, teve origem em outra exitosa experiência desenvolvida em 1971 no Vale do Jequitinhonha, também em Minas Gerais, e que adquiriu notoriedade pelo caráter inovador de suas propostas. Essas experiências se propunham a formular

um novo modelo de organização de serviços, novas práticas pedagógicas, transformação radical das relaçóes no interior da equipe de saúde, participação cidadã da comunidade e dos servidores, práticas inovadoras no planejamento e gestão e autonomia e fortalecimento do nível local. (Fleury, 1995: 14)

As estratégias dos Programas de Extensão de Cobertura (PEC) caracterizavam-se pela necessidade de incorporar grupos populacionais de comunidades carentes até então excluídos do consumo de serviços de saúde, e sua adoção pelos países foi parte integrante das conclusões da III Reunião Especial dos Ministros de Saúde das Américas realizada em Santiago do Chile em 1972, quando se elaborou o Plano Decenal de Saúde das Américas (Teixeira, 1982).

O Piass se organizou com base nas propostas sugeridas pelo Plano Decenal para os Programas de Extensão de Cobertura. Sua implantação no país se deu sob a coordenação do Ministério da Saúde, que programou uma estratégia conjunta com o Programa de Preparação Estratégica do Pessoal de Saúde (Ppreps). Este, por sua vez, contava com apoio expressivo da Opas.

A idéia de expansão de cobertura associada à medicina comunitária já vinha sendo discutida no interior das universidades brasileiras, sem, no entanto, alcançar reconhecimento por parte do governo, no sentido da incorporação do seu modelo. A universidade adotou essa idéia precocemente através do Projeto Montes Claros que assumiu como estratégia política uma intensa articulação com a Secretaria Estadual de Saúde de Minas Gerais e com outros espaços do sistema de saúde, receptivos às idéias de um programa de extensão de cobertura com essas características, assim definidas: 
Como um laboratório de democratização na saúde, ali foram conceitualizados, montados e testados alguns dos principais instrumentos daquilo que posteriormente veio a ser conhecido como o processo da Reforma Sanitária, tais como a produção de um saber sobre a causação social da saúde/doença, a difusão de uma nova consciência sanitária e a estratégia de ocupação e/ou criação de espaços político-institucionais. (Fleury, 1995: 14)

Os produtos desse trabalho passaram a ser divulgados, estrategicamente, através de visitas e seminários, criando condições para a sua experimentação e o debate em outras realidades.

A absorção da experiência pelo Ministério da Saúde, através do Piass, possibilitou a capilarização dos resultados para outras regiões do país, contando, nessa expansão nacional, com o apoio do Ppreps, também do Ministério da Saúde, como parte integrante do acordo interministerial MS/Opas/MEC para a área de recursos humanos em saúde. Os dois programas atuaram de forma sinérgica, apoiando estruturas estaduais do sistema de saúde e difundindo práticas de planejamento voltadas para a estruturação do setor. Essa difusão em todo o país permitiu o engajamento de grupos de técnicos progressistas que trabalhavam em secretarias estaduais de Saúde, muitos dos quais oriundos de cursos de Saúde Pública da Ensp/Fiocruz ou da FSP/USP.

Com a criação do Ppreps, as políticas de recursos humanos assumiram um papel de destaque no âmbito do Ministério da Saúde. Coerente com as diretrizes do II PND, no que se refere ao desempenho dos serviços públicos, o programa visou a reformular as práticas de gestão e de capacitação de recursos humanos até então desenvolvidas de forma dispersa pelas secretarias estaduais de Saúde e pela Fundação Serviços Especiais de Saúde Pública (Fsesp), tanto no que se refere a formação de pessoal auxiliar, como aa formação de pessoal de nível superior.

O Ppreps foi desenvolvido por uma equipe composta por representantes dos Ministérios da Saúde, Educação e Cultura, e da Opas, através de um acordo interministerial que deu base legal a três grandes objetivos: ${ }^{3}$

Preparação, em massa, de pessoal de nível médio (técnico e auxiliar) e elementar, para cobrir os déficits existentes e previstos, permitindo a extensão de cobertura e a melhoria dos serviços; apoio à constituição, implementação e funcionamento

\footnotetext{
${ }^{3}$ Em março de 1980, um novo instrumento jurídico introduziria o Ministério da Previdência e Assistencial Social como uma das partes do acordo de cooperação técnica entre o governo brasileiro e a opas que permitiu o financiamento do Ppreps. Esta nova base institucional parecia refletir um esforço para imprimir maior integração entre as principais áreas federais que compunham a atenção à saúde no país (Pires-Alves \& Paiva, 2006).
} 
de 10 regiões docente-assistenciais para uma cobertura final de 15 a 20 milhões de habitantes; apoio ao estabelecimento de Sistemas de Desenvolvimento de Recursos Humanos para a saúde, em cada Estado da Federação, integrados aos sistemas de planejamento setorial respectivo. (Teixeira, 1982: 65)

O desenvolvimento do Ppreps, pelas estruturas de governo, foi mais uma experiência associada ao projeto expansionista e racionalizador do sistema público de saúde da época que, embora não tenha alterado a correlação de forças dada pelas definições dos papéis dos Ministérios da Saúde e da Previdência no plano governamental, tornou-se um instrumento importante de aglutinação de idéias das equipes dos serviços e das universidades que vinham exercendo a crítica ao modelo vigente.

A abertura programática do Ppreps referente à integração docente-assistencial favoreceu a aproximação de equipes dos ministérios envolvidos e da Opas, com as experiências em curso nas universidades, ligadas à temática da medicina comunitária, traduzidas em projetos que já vinham discutindo alternativas de práticas para o sistema de saúde da época, entre os quais se destacavam (Santos, 1995):

- Programa de Medicina Comunitária de Londrina-Paraná, patrocinado pela Universidade de Londrina, em convênio com a Prefeitura Municipal, em 1969;

- Projeto de Saúde Comunitária da Unicamp (Campinas-SP), conhecido como Projeto Paulínia, financiado pela Fundação Kellogs, e que teve início entre 1971 e 1972 ;

- Programa de Saúde Comunitária - Projeto Vitória - realizado pela Universidade Federal de Pernambuco em Vitória de Santo Antão, PE;

- O Projeto de Atuação Médica Simplificada, para uma área periurbana do estado do Rio de Janeiro. Patrocinado pelo Instituto de Medicina Social da Universidade do Estado do Rio de Janeiro (IMS/Uerj), em Nova Iguaçu, RJ;

- Projeto de Área Programática para Serviços Integrados de Saúde - USP/ DMP e Secretaria de Saúde de São Paulo.

A relação entre a temática da formação de recursos humanos e a reestruturação do sistema de saúde estava expressa nas ações previstas pelo Ppreps. A sua implantação conjunta com o Piass facilitou a integração ensino x serviço e com ela a problematização do Projeto de Sistema de Saúde, permitindo avançar na busca de alternativas, também discutidas pelas universidades e pelos serviços de saúde.

Dessa forma, o Ppreps pode ser considerado:

Um instrumento de intervenção estatal na área de formação de pessoal, visando contribuir para a implantação e o fortalecimento de um dado modelo de atenção 
à saúde, que se caracteriza por tomar como objeto as populações excluídas do consumo de serviços sob as modalidades dominantes de atenção. É assim, um elemento de um projeto político de setores avançados das instituições estatais, especialmente o Ministério da Saúde, que sob a influência das organizações internacionais buscavam 'modernizar' as formas de participação do Estado na organização das práticas de saúde. (Teixeira, 1982:68)

A integração ensino-serviço, na perspectiva adotada pelo Piass, associada ao Ppreps, favoreceu a ampliação de projetos que se desenvolveram de forma experimental, valorizando as iniciativas em andamento e ampliando o seu espectro no interior dos departamentos de Medicina Preventiva, através da idéia de medicina comunitária, conforme analisa Paim (1986: 111):

o movimento da Medicina Comunitária é inicialmente incorporado pelos Departamentos de Medicina Preventiva que passam a testar novas modalidades de treinamento de pessoal, articuladas a alguma experiência de organização de serviços de saúde. Tais iniciativas, originariamente limitadas e focais, vão sendo ampliadas tanto em nível dos serviços de saúde através dos programas de extensão de cobertura (PECs), como em nível do ensino mediante a integração docente-assistencial.

Vale ressaltar que a integração docente-assistencial foi também concebida como um processo social, integrante das mudanças globais da sociedade naquele período. Considerava-se fundamental a participação da comunidade nas políticas públicas engendradas pelo Estado; uma maior articulação entre instituições, sem, contudo, comprometer a individualidade delas; e, sobretudo, a promoção de um processo de ensino-aprendizagem em sintonia com a realidade concreta das populações e com a participação do aluno em seu desenvolvimento, nos currículos e conteúdos acadêmicos (Marsiglia, 1995). ${ }^{4}$

Foi possível detectar que as estratégias desenvolvidas pelo governo, nesse período, produziram resultados no campo da capacitação de pessoal auxiliar e na gestão de recursos humanos e, por meio do Ppreps, foi possível desenvolver, nas secretarias de Estado, o entendimento das noções de planejamento de recursos humanos, ampliando assim as possibilidades de relação desses espaços

${ }^{4}$ As idéias originárias da Medicina Comunitária se expandiram por muitas universidades brasileiras durante as décadas de 70 e 80 e "foram incorporadas pelos técnicos das instituições estatais do Brasil e encontram-se no bojo da série de iniciativas surgidas após a $5^{\text {a }}$ Conferência Nacional de Saúde, com a criação do Sistema Nacional de Saúde (Lei 6.229 de 1975), do Programa Materno Infantil, do Programa Nacional de Imunizações, do Sistema Nacional de Vigilância Epidemiológica, Programa Especial de Controle da Esquistossomose-Pece, o Piass e finalmente o Programa Nacional de Serviços Básicos de Saúde-Prevsaúde, em 1980" (Teixeira, 1982: 52-53). 
burocráticos com as políticas de formação de sanitaristas desenvolvidas até então de forma centralizada, pela Ensp e pela FSP/USP, e que, a partir de 1975, principalmente a partir da Ensp, projeta-se na experiência de cursos descentralizados, provocando uma completa reformulação na oferta desses cursos e permitindo a entrada de sanitaristas em larga escala nos serviços estaduais de saúde, e com uma formação que já absorvia os elementos da conjuntura.

A contribuição do Ppreps foi também expressiva na criação e desenvolvimento de núcleos de Recursos Humanos nas secretarias estaduais de Saúde, possibilitando "a formação de intelectuais orgânicos, não somente para um projeto racionalizador, mas também para o movimento de democratização da saúde" (Paim, 1994: 38). Desta forma, o Programa de Preparação Estratégica de Pessoal de Saúde pode constituir um bom exemplo das interfaces entre a reforma sanitária e a necessidade de adequação da formação de pessoal às necessidades do sistema de saúde.

Essa sintonia, contudo, como veremos mais adiante, náo deve ser compreendida no quadro de uma submissão do campo de recursos humanos às necessidades imperiosas dos reformadores do sistema, tendo em vista o fato da formação de pessoal de saúde não apenas possuir um desdobramento em políticas públicas, mas também constituir, pouco a pouco, um domínio cognitivo, de pensamento e elaboração teórica.

\section{Do natimorto Prevsaúde ao SUS sancionado como lei: a década de 80 e a construção democrática}

Nos anos 80, ocorreu uma intensa pressão da sociedade civil por participação e por liberdades democráticas, marcando a insatisfação da sociedade com o prolongamento do regime ditatorial e os seus desdobramentos. Símbolo da efervescência dessa fase, o movimento das Diretas Já, em 1984, defendendo o direito ao voto direto na escolha do presidente da República, aglutinou essas insatisfações com manifestações expressivas em todo o território nacional.

Foi uma década muito importante para a consolidação do movimento relacionado às mudanças no sistema de saúde brasileiro e à formação de recursos humanos para a saúde, e que se inicia com a realização da $7^{\text {a }}$ Conferência Nacional de Saúde, em Brasília, em março de 1980, tendo, como tema central, "A extensão das ações de saúde através dos serviços básicos".

A partir da leitura do relatório dos debates travados na ocasião, podem-se perceber os limites das propostas institucionais apresentadas, em função do real sistema de saúde brasileiro, que já se tornara complexo, e cuja concentração de recursos no Ministério da Previdência limitava as possibilidades de desempenho do Ministério da Saúde, nas ações de sua competência (Anais da $7^{a}$ CNS, 1980). 
A $7^{\text {a }}$ Conferência produziu um debate e uma síntese que mobilizaram apoios e oposições a prováveis intervenções nas políticas de saúde pela via estatal, nascendo, no interior do governo, o Programa Nacional de Serviços Básicos de Saúde (Prevsaúde). ${ }^{5}$ O seu processo de formulação se caracterizou por uma polarização entre o que era considerado estatizante e privatizante nas políticas de saúde e propiciou um debate que incorporou profissionais do setor, dirigentes públicos e representantes de entidades profissionais. A reação contrária estava representada pelos empresários da saúde, principais beneficiários da política de privatização que vinha sendo implantada com o financiamento do Estado (Oliveira \& Fleury, 1986).

O Prevsaúde se referenciou nos resultados das experiências de atenção primária como a de Montes Claros, em Minas Gerais, e a do Piass, no Nordeste, incorporando como pressupostos básicos: a hierarquização das formas de atendimento por níveis de complexidade; a cobertura em áreas carentes; a atenção primária como porta de entrada do paciente no sistema de saúde; a participação comunitária e as técnicas simplificadas; a integração dos serviços existentes em cada um dos níveis de complexidade, independente da sua vinculação como público ou privado; e a regionalização do atendimento por áreas e populações definidas (Oliveira \& Fleury, 1986).

O modelo assumido pelo Prevsaúde dava continuidade aos debates da $7^{\mathrm{a}}$ Conferência e incorporava uma estruturação de sistema, interpretada por alguns como estatizante. Em sua última versão, o Prevsaúde se transforma em uma proposta mais normativa do que estruturante do setor. Para Oliveira e Fleury, houve alterações na essência do plano antes de ele vir oficialmente a público. Estas mudanças o descaracterizaram, convertendo-o apenas em um projeto de racionalização do modelo vigente, o Plano de Reorientação da Assistência à Saúde Previdenciária, que foi editado junto com a criação do Conselho Consultivo da Administração de Saúde Previdenciária (Conasp).

Frustraram-se, com o Prevsaúde, as expectativas criadas a partir das conclusões da $7^{\text {a }}$ Conferência, quanto a uma possível renovação do sistema de saúde, pactuada entre os ministérios da Saúde e da Previdência e Assistência Social. A pressão exercida no interior do processo de construção do Prevsaúde pelos atores das negociações encerradas sem êxito, somada às dificuldades

\footnotetext{
${ }^{5}$ O Programa Nacional de Serviços Básicos em Saúde é elaborado por um grupo de técnicos composto por representantes dos ministérios da Saúde e da Previdência Social, com vistas à reestruturação e ampliação dos serviços de saúde, compreendendo também as áreas de saneamento e habitação (Fleury \& Teixeira, 1986).
} 
financeiras da Previdência, ${ }^{6}$ resultou na elaboração do Plano de Reorganização da Assistência à Saúde no âmbito da Previdência Social, divulgado pelo Conselho Consultivo da Administração de Saúde da Previdência (Conasp) e aprovado em em agosto de 1982, pela Portaria n. 3.062. ${ }^{7}$ O documento apresentado pelo Conasp propôs medidas quanto ao modelo vigente de prestação de serviços de saúde no âmbito da Previdência Social, reorientando a assistência à saúde previdenciária e definindo também as estratégias para sua implementação (Oliveira \& Fleury, 1986).

O Plano apontou para a definição de parâmetros de cobertura e de concentração de serviços hospitalares, ambulatoriais e complementares de diagnóstico e tratamento para disciplinar o atendimento dos serviços vinculados ao Inamps (Portaria MPAS n. 3.046/82); para a reordenação burocrático gerencial de hierarquização das consultas médicas e serviços complementares, em linhas de atendimento, através do projeto de racionalização ambulatorial, que era limitado aos ambulatórios privados; e para a adoção de procedimentos normativos, vinculados às internações no setor privado aos leitos contratados pelo Inamps e limitando o abuso de expansões crescentes das internações nesse setor (Cordeiro, 1991).

As considerações aqui efetuadas são ilustrativas de uma crise que vinha se evidenciando em múltiplas facetas, desde a década de 60 , no âmbito da Previdência Social, tornando cada vez mais clara a inviabilidade do modelo de assistência e de financiamento do sistema de saúde, nos moldes estabelecidos.

$\mathrm{O}$ aprofundamento das questões abordadas com relação ao modelo e ao financiamento da saúde fugiria às finalidades deste trabalho, mas apresentam alguns dados do contexto, em que foi possível avançar para a implantação da estratégia das AIS, surgidas também no âmbito da Previdência e Assistência Social, e que se tornou um caminho que possibilitava a construção de alianças entre os ministérios envolvidos com a saúde, o mesmo ocorrendo com as suas correspondentes estruturas estaduais e municipais.

\footnotetext{
${ }^{6}$ A chamada crise financeira da Previdência Social caracterizou-se pela existência de um déficit crescente a partir de 1980, atingindo neste ano os 40 bilhões de cruzeiros, sendo que, no início de 1981, no ápice da crise, já superava a casa dos 150 bilhões, A essa época, as projeções existentes previam a elevação do déficit a mais de 200 bilhões até o final de 1981, representando 1/6 do orçamento total para 1981, e mais de 400 bilhões para fins de 1982 (Oliveira \& Fleury, 1986).

${ }^{7}$ O Conselho foi "criado em 2/9/81, através do decreto n. 86.329 do presidente da República como órgão do Ministério da Previdência e Assistência Social, com a competência de operar sobre a organização e áperfeiçoamento da assistência médica, sugerir critérios de alocação de recursos previdenciários para esse fim, recomendar políticas de financiamento e de assistência à saúde, analisar e avaliar a operação e o controle da Secretaria de Assistência Médica da Previdência Social" (Oliveira \& Fleury, 1986: 291).
} 
representavam o início da incorporação dos setores público e privado nas atividades de planejamento que romperiam com a concepção dominante da dicotomia entre serviços/ações preventivas e curativas, ainda que o enfoque do planejamento se vinculasse estritamente à capacidade instalada de assistência individual.

No âmbito da saúde, o governo implantou, em 1983, como experimental, a estratégia de AIS, ampliada para todo o país em 1984. Estas ações representavam um avanço em relação ao processo de gestão até então adotado pelo sistema de saúde, introduzindo a proposta de gestão colegiada de ações de saúde, envolvendo, além do Ministério da Previdência e Assistência Social, os ministérios da Educação e da Saúde, e expandindo-se pelos níveis federal, estadual e municipal (Paim, 1986).

Embora de cunho eminentemente racionalizador, as AIS tiveram o mérito de abrir, para estados e municípios, a possibilidade de também se transformarem em atores da política nacional de saúde, seja como participantes dos fóruns de discussões oficiais (Comissão Interinstitucional/CıS, Comissão Interinstitucional Municipal de Saúde/CIMS) ou não oficiais que então se abriam, seja como receptores de 'novas' (mas na verdade antigas) responsabilidades no sistema de saúde (Goulart, 1996).

A proposta das AIS incorporou uma visão de gestão colegiada que se expressava em comissões localizadas nos vários níveis do sistema. No plano federal, a Comissão Interministerial de Planejamento (Ciplan) envolvia os ministérios da Saúde, da Previdência e Assistência Social, e Educação e Cultura, incorporando, posteriormente, o Ministério do Trabalho. As CIS, CRIS e CIMS (comissões interinstitucionais estaduais, regionais e locais de saúde) compunham a concepção que permitia a formalização de espaços de troca (Cordeiro, 1991).

Ainda que as decisões dependessem da aprovação das instâncias centrais, estava instalado, através desse mecanismo, um processo de gestão colegiada que lançaria as bases para outras mudanças, que passariam a defender a democratização, como prática inerente ao processo de planejamento e gestão das instituições. Ressalte-se que a associação entre democratização e saúde já estava disseminada no interior do movimento sanitário e representava a marca registrada das produções do Cebes, desde a sua criação, em 1976.

A luta empreendida, até então, para reformular o sistema de saúde e construir uma nova relação do Estado com a sociedade através da saúde se deslocava do Ministério da Saúde, palco das inovações ocorridas na segunda metade da década de 70, para o Ministério da Previdência e Assistência Social, até então fortalecido como estrutura de recursos e de poder, mas que resistia atra- 
vés de mecanismos formais, às mudanças que aos poucos vinham sendo debatidas nos fóruns políticos promovidos pela Abrasco e pelo Cebes.

$\mathrm{O}$ avanço do processo de implantação das AIS favoreceu ainda a criação de comissões com participantes que representavam pensamentos políticos variados e ideologicamente divergentes em relação às concepções de Sistema de Saúde. Este fato também estimulou a manutenção de um debate permanente em torno dessas questões, permitindo o envolvimento de grupos representativos que buscavam a atualização das propostas relativas às políticas de saúde. Os fóruns contavam com a participação das instituições universitárias, Cebes, Abrasco, comissões de saúde dos partidos políticos, entidades de profissionais de saúde, de trabalhadores urbanos e rurais e pelo movimento da reforma sanitária. Desta forma, nas palavras de Hésio Cordeiro (1991: 37), "as AIS proporcionavam uma base técnica e princípios estratégicos para os momentos posteriores da Reforma Sanitária, mas estavam longe de ser, na prática, uma política de saúde assumida pelo governo".

Com essa perspectiva, vale destacar a realização de duas reuniões, durante o ano de 1984, promovidas pela Comissão de Saúde da Câmara dos Deputados (Simpósio das Políticas de Saúde) e pelo Cebes e pela Abrasco, em Brasília e em Curitiba, respectivamente. No Simpósio de Políticas de Saúde da Câmara dos Deputados, que contou com a participação de representantes do movimento sanitário e de entidades privadas prestadoras de serviços "só houve consenso quanto ao diagnóstico de que era necessário ampliar as dotações para a saúde" (Cordeiro, 1991: 39), mas foi expressivo o debate em torno das AIS como caminho para a estruturação de um novo sistema de saúde (Paim, 1986).

A reunião do Cebes e da Abrasco, realizada em Curitiba, fortalecia as posições do movimento sanitário, sobretudo no que se referia à necessidade de promoção da unificação do sistema de saúde, a descentralização, à participação da população nas decisões e a fiscalização. Reconhecia-se o programa das AIS como um passo decisivo para e preparação da base técnica e gerencial do setor público para as reformas da saúde (Cordeiro, 1991).

$\mathrm{Na}$ direção municipal, as AIS também permitiam aprofundar mecanismos necessários à construção do sistema único. o compromisso com o sistema único de saúde por parte dos secretários municipais manifestou-se através da carta de Montes Claros, apelidada de 'Muda Saúde', fruto da Reunião de Secretários Municipais, ali realizada em janeiro de 1985. Neste documento, os secretários se manifestaram também sua confiança no processo de municipalização (Goulart, 1996). Nesse sentido é exemplar o depoimento de Goulart, então secretário municipal de Saúde de Uberlândia:

As AIS foram mais do que a abertura possível. Foi um espaço em que nós, Secretários Municipais de Saúde, entramos como convidados, a princípio, mas 
logo percebemos que era um foco de luta e de conquista... fomos construindo uma rede de contatos que, até então, não existia. Em pouco tempo já estávamos empolgados com as novas possibilidades do novo Sistema. (Goulart, 1996: 20)

Aos poucos, a estratégia das AIS ia permitindo a ampliação dos grupos envolvidos com os conteúdos críticos do sistema de saúde em vigor e proporcionando um espaço público de discussão das políticas de saúde. Em palestra proferida durante o III Congresso Médico Social da Bahia, em novembro de 1985, sobre a "Reorganização dos Serviços de Saúde e Ações Integradas de Saúde - AIS", Paim teve oportunidade de apresentar dez motivos para apostar nessa estratégia, assim mencionados:

- Princípios e objetivos consistentes, com a democratização da saúde;

- Planejamento e administração descentralizados;

- Instâncias deliberativas permeáveis à negociação política;

- Possibilidade concreta de participação popular organizada;

- Percurso para o estabelecimento do Sistema Unificado de Saúde;

- Respeito ao princípio federativo;

- Respaldo de forças sociais atuantes no setor;

- Perspectiva mais concreta de viabilidade;

- Incorporação do planejamento à prática institucional;

- Responsabilidade das universidades de formulação e desenvolvimento de políticas de saúde. (Paim, 1986: 193)

O debate em torno das AIS deu origem a alguns documentos propositivos então encaminhados ao presidente Tancredo Neves, com uma "convergência doutrinária informada pelo movimento sanitário e pela idéia do Sistema Único de Saúde" (Rodriguez Neto, 1997: 68). Segundo Rodriguez Neto, dois documentos se destacaram pela identidade nos pontos essenciais. o documento da Comissão de Elaboração do Plano de Ação do Governo Tancredo Neves (Copag), que contou com a participação de vários integrantes do movimento sanitário, e o segundo, apresentado por um grupo de parlamentares do Partido do Movimento Democrático Brasileiro (PMDB), que "tinha uma clara intenção de disputar um espaço, assumindo a condução da política de saúde" (Rodriguez Neto, 1997: 69).

Os documentos eram cautelosos quanto aos prestadores privados de serviços de saúde, "não indo além das propostas do Conasp e das intenções de dar prioridade ao setor público e às entidades filantrópicas" (Cordeiro, 1991: 40).

o Simpósio de Saúde da Câmara dos Deputados, realizado em 1984 na Câmara de Deputados, reforçou, em seu documento final, a estratégia das AIS como um caminho para o sistema único de saúde, ampliando o espaço de negociação com o programa de governo da transição democrática (Paim, 1986), 
base da formulação da política de saúde do que viria a ser o governo de Tancredo Neves. O seu substituto, o presidente José Sarney, convocou, em 1985, a $8^{a}$ Conferência Nacional de Saúde, dando continuidade a essa formulação.

Em março de 1986, realizou-se, em Brasília, a $8^{\text {a }}$ Conferência Nacional de Saúde, convocada José Sarney e com ampla participação de trabalhadores e de representações da sociedade civil organizada - diferente das anteriores, que só permitiam a participação de representantes do governo.

A $8^{\text {a }}$ Conferência foi antecedida por conferências estaduais, propiciando o debate ampliado sobre seus temas centrais: saúde como direito inerente à cidadania e à personalidade; reformulação do sistema nacional de saúde e financiamento do setor saúde.

A organização desses debates foi impregnada, em todo o país, pela movimentação política que já se expressava em fóruns anteriores como o Simpósio Nacional da Câmara dos Deputados e as reunióes do Cebes e da Abrasco. Foram elaborados documentos sobre as temáticas da Conferência e os docentes vinculados à Abrasco e ao Cebes se deslocaram para os diversos pontos do país proferindo palestras na etapa estadual que antecedeu a Conferência Nacional, com uma expressiva participação de segmentos da sociedade organizada.

Para dar continuidade aos resultados da $8^{\text {a }}$ Conferência, duas vertentes se estabeleceram: um grupo de trabalho sob a coordenação do Ministério da Saúde, constituindo o que foi denominado de Comissão Nacional da Reforma Sanitária, que realizou um trabalho com as instituiçóes governamentais, e uma outra vertente que atuou junto ao Congresso Nacional com uma representação delegada pelas entidades de saúde, tendo em vista o processo constituinte em andamento nesse período. O Núcleo de Saúde Coletiva da Universidade de Brasília teve um papel fundamental nessa articulação, negociando as propostas que emanavam do movimento da reforma sanitária e que eram discutidas na Plenária da Saúde, grupo que se reunia regularmente em Brasília, integrado pelas diversas entidades da saúde em torno da Reforma Sanitária.

Vale destacar que a Comissão Nacional da Reforma Sanitária dedicou atenção especial à questão de recursos humanos, produzindo documentos técnicos em que foram identificados os nós críticos do sistema de saúde ligados ao tema, trazendo novas questões para o debate, no que diz respeito à preparação de quadros para o sistema de saúde.

A $8^{\text {a }}$ Conferência definiu, entre as suas conclusões, que alguns temas estratégicos para organização do sistema de saúde deveriam ser objeto de conferências específicas. Entre os assuntos escolhidos, destacou-se 'recursos humanos'.

A I Conferência de Recursos Humanos abordou os temas da valorização do profissional, da preparação de recursos humanos, dos órgãos de desenvolvimento de recursos humanos para a saúde; da organização dos trabalhadores 
de saúde e da relação do trabalhador de saúde como usuário do sistema. Entre os tópicos relativos à preparação, o programa da conferência destacou a formação pós-graduada como relevante para o setor saúde, recomendando ainda uma relação com o sistema de saúde assim estabelecida: "a formação ulterior deve ser definida em função das necessidades do Sistema Único de Saúde de dispor de profissionais e equipes qualificadas para dar conta de modo eficiente (em termos de custo) e eficaz (em termos de resultados), de questões específicas referentes a problemas menos freqüentes". Estabeleceu também que "a estruturação do sistema em níveis hierarquizados de atenção à saúde deve fornecer os critérios, conforme os quais as necessidades quantitativas e qualitativas de formação posterior à graduação devem ser atendidas" (Brasil, 1986: 30).

Nesse contexto pós $8^{a}$ Conferência Nacional de Saúde, surgiu uma nova linha de cursos, apoiada pelo Ministério da Saúde, que se recortava por temáticas (de recursos humanos, de planejamento e de vigilância sanitária). Estes cursos eram oferecidos aos profissionais que já estavam nos serviços de saúde, em secretarias estaduais, principalmente, mas incorporando aos poucos os técnicos das secretarias municipais.

Essa linha diversificou a tradicional oferta de cursos de formação em saúde pública oferecidos pelas escolas de saúde pública, que eram, até aquele momento, os principais programas de preparação de quadros para as funções típicas dos sanitaristas lotados nessas instituições.

Os cursos novos surgem no contexto da criação dos Núcleos de Estudos em Saúde Coletiva na Nova República. Os núcleos foram criados com o apoio do Ministério da Saúde como uma ação indutora daquele Ministério para dar resposta à expectativa de uma rápida estruturação do Sistema Único de Saúde, nas bases apontadas na $8^{a}$ Conferência.

Os núcleos tinham inserções variadas, porém estavam mais concentrados em universidades, nos diversos pontos do país, instituindo um novo ator social entre aqueles já existentes, as escolas de saúde pública ligadas às secretarias estaduais e os departamentos de medicina preventiva, além das escolas de saúde pública da Universidade de São Paulo e da Fundação Oswaldo Cruz, consideradas escolas nacionais.

O reordenamento das estruturas de formação nos diversos pontos do país, além de possibilitar a oferta de cursos de curta duração voltados para áreas estratégicas do Sistema de Saúde, reconfigurou a capacidade de resposta desses centros de formação às secretarias estaduais e municipais de Saúde, diversificando a oferta de cursos lato sensu para a saúde pública.

A mobilização dos diversos segmentos do setor saúde que se identificavam com as idéias da Reforma Sanitária não se encerrou com a $8^{a}$ Conferência, e, com a avaliação de que deveria ser instituído um modelo intermediário às AIS, organiza-se, a partir de 1987, o Sistema Unificado e Descentralizado de 
Saúde (Suds), implantado por convênios entre o governo federal e os estados, configurando uma alteração significativa nas orientações do processo decisório até então vigente.

Pelas novas regras, o Inamps perdeu seu papel de prestador de serviços (tanto direto, quanto indireto) tornando-se um órgão controlador e co-financiador do sistema de saúde, com uma prestação de serviços que passaria a ser efetuada de forma descentralizada pelos estados e municípios. Seu planejamento passaria, igualmente, a ser realizado de forma descentralizada, procurando evitar o paralelismo de iniciativas e buscando maior resolutividade, universalização, regionalização, hierarquização e integralidade das ações de saúde (Muller, 1992).

Nesse quadro, os convênios com os estados assumiram formas variadas, "contemplando diferentes níveis de transferência de funções bem como abarcando diferentes esferas descentralizadas de governo", indicando que "a intenção dos dirigentes da Previdência Social em promover a descentralização acelerada, era testar, na prática, a alternativa que parecia mais viável de melhoria da prestação de serviços para o usuário" (Muller, 1992: 51).

A implantação do Suds não foi realizada sem resistência, em que pese o reconhecimento da legitimidade dos resultados da $8^{\text {a }}$ Conferência e a condução política dos dirigentes do Inamps, que buscavam dar coerência aos princípios descentralizadores embutidos nas diretrizes do Suds. O teste do modelo de cunho descentralizador, referido por Muller, significava uma mudança radical nas formas de gestão até então existentes, de natureza privatista e centralizadora.

Esse processo político-social mobilizou enfrentamentos, que permitiram a problematização da realidade da prestação de serviços de saúde. Em torno dele, aglutinaram-se forças consideradas progressistas, representadas por pessoas que, através de suas entidades ou instituições, apoiavam a Reforma Sanitária e a criação do novo sistema de saúde - que, a esse tempo, ainda não tinha sido sancionado como lei, pelo Congresso Nacional.

Os embates políticos favoreceram a organização maior do movimento de trabalhadores, de parlamentares e de entidades representativas da sociedade, possibilitando a incorporação da saúde como um direito social na Constituição de 1988, que, em seu artigo 194, estabeleceu as ações de iniciativa dos poderes públicos e da sociedade, destinado a assegurar os direitos relativos à saúde, à previdência e à assistência sociais, assim definidas:

universalidade da cobertura e do atendimento; uniformidade e equivalência dos benefícios e serviços às populações urbanas e rurais; seletividade e distributividade na prestação dos benefícios e serviços; irredutibilidade do valor dos benefícios; equidade na forma de participação no custeio; diversidade 
da base de financiamento; caráter democrático e descentralizado da gestão administrativa, com a participação da comunidade, em especial dos trabalhadores, empresários e aposentados. (Brasil, 1988: 131)

Em seu artigo 196, a Constituição definiu também que "a saúde é direito de todos e dever do Estado, garantido mediante políticas sociais e econômicas que visem à redução do risco de doença e de outros agravos e ao acesso universal e igualitário às ações e serviços para a sua promoção, proteção e recuperação" (Brasil, 1988: 133).

A Constituição estabeleceu em seu artigo 200 que:

Compete, ao Sistema Único de Saúde, além de outras atribuições, nos termos da lei:

Controlar e fiscalizar procedimentos, produtos e substâncias de interesse para a saúde e participar da produção de medicamentos, equipamentos, imunobiológicos, hemoderivados e outros insumos;

- Executar as ações de vigilância sanitária e epidemiológica, bem como as de saúde do trabalhador;

- Ordenar a formação de recursos humanos na área da saúde;

Participar da formulação da política e da execução das ações de saneamento básico;

Incrementar em sua área de atuação o desenvolvimento científico e tecnológico;

- Fiscalizar e inspecionar alimentos, compreendido o controle de seu teor nutricional, bem como bebidas e águas para consumo humano;

Participar do controle e fiscalização da produção, transporte, guarda e utilização de substâncias e produtos psicoativos, tóxicos e radioativos;

Colaborar na proteção do meio ambiente, nele compreendido o do trabalho. (Brasil, 1988: 133)

A síntese apresentada neste capítulo passa necessariamente pelo esclarecimento de que o movimento crescente que se estabeleceu nas experiências mencionadas, nos ministérios, nas universidades, nas secretarias estaduais e municipais e nos centros formadores em geral não pode ser analisado com um caráter linear. As forças progressistas mencionadas apresentaram, nesse período, um nítido poder de articulação que será analisado nos próximos capítulos.

Durante esse período, algumas instituições consideradas 'conservadoras', incorporaram-se aos movimentos de mudanças, produzindo uma alteração na correlação de forças no interior do governo, ao longo das décadas estudadas.

O exemplo mais emblemático é o Inamps, que inicia os anos 70 vinculado ao Sistema Nacional de Saúde através do Ministério da Previdência e Assistência Social, com políticas de cunho privatizante, e, a partir de meados dos 
anos 80 , assume gradualmente uma posição radical de revisão de suas atividades no âmbito de um sistema de saúde já impregnado pelas idéias de um sistema único de saúde, e dentro dele, conseguiu produzir ações descentralizadoras significativas para a consolidação do SUS, transformado em lei, em 1990.

Também se procurou sinalizar para a existência de um conjunto de centros escolares do campo da saúde pública, cuja expansão foi expressiva nas décadas de 70 e 80 , e que se organizou na interação entre si e com outros parceiros, relacionando-se, intensamente, com as políticas de saúde e com o contexto político, nas distintas conjunturas. 